\title{
Multi-Objective Portfolio Optimization of Electricity Markets Participation
}

\author{
Ricardo Faia ${ }^{1}$, Tiago Pinto ${ }^{2}$, Zita Vale ${ }^{1}$, Juan Manuel Corchado ${ }^{2}$ \\ ${ }^{1}$ GECAD Research Center - Polytechnic of Porto \\ Porto, Portugal \\ $\{$ rfmfa, zav\}@isep.ipp.pt \\ ${ }^{2}$ BISITE Research Centre - University of Salamanca \\ Salamanca, Spain \\ \{tpinto, corchado\}@usal.es
}

\begin{abstract}
Power and energy systems are being subject to relevant changes, mostly due to the large increase of distributed generation. These changes include the deregulation of electricity markets, which has become a more competitive marketplace due to the increase of the number of players based on renewable energy sources. This paper proposes a new portfolio optimization model for the participation in multiple alternative / complementary market opportunities, considering the risk management. The proposed model considers electricity as the asset to be negotiated. The risk is measured using the prediction error of electricity prices. A case study based on real data from Iberian electricity market - MIBEL assesses the results of the proposed model, using a particle swarm based optimization. Results show that using the proposed portfolio optimization model, market players are able to balance their market participation strategies depending on their risk aversion and profit seeking nature.
\end{abstract}

Index Terms--Distributed generation, Decision Support, Electricity Markets, Portfolio Optimization.

\section{INTRODUCTION}

The electric sector has undergone numerous changes, which arose from the need to reduce energy production based on fossil fuels [1]. So that the production of electricity through fossil fuels can be reduced, the governmental institutions agreed to a set of directives [2] where they imposed an increase of the electricity produced by fuels of renewable origin. As a consequence of these actions, the generation from renewable sources increased, causing a decentralization of the system, since most of this generation is distributed.

On the other hand, as most Distributed Generation (DG) is based on renewable sources, the power system needs to deal

The present work was done and funded in the scope of the following projects: NetEfficity Project (P2020 - 18015), European Union's Horizon 2020 research and innovation programme under the Marie SklodowskaCurie grant agreement No 703689 (project ADAPT); and UID/EEA/00760/2013 funded by FEDER Funds through COMPETE program and by National Funds through FCT. with additional challenges that arise from the variability of renewable based generation [3]. In order to support the involved players decisions in this constantly changing environment, several simulators have emerged, many of these based on Multi-Agent Systems (MAS) [4]. MAS simulators enable studying power and energy systems and anticipating future negotiations. These simulators use different artificial intelligence (AI) techniques, namely for data collection, analysis, forecasting and optimization. Several examples of simulators based on MAS technology can be found in the literature. MASCEM (Multi-Agent Simulator of Competitive Electricity Markets) [4], is one of these simulators, and allows simulating the Electricity Market (EM) environment, supporting several market models that can be found in different countries. These EM simulators are mostly suited for studying EM operation, thus presenting a significant gap in the decision support for EM participants' actions.

The portfolio optimization in the energy sector can be a risk management tool and also a tool that supports EM players' decisions. So that stakeholders can maximize their benefit from the participation in the liberalized EM, decision support that allows the necessary assistance becomes crucial, so that they can carry out their actions safely and with knowledge of what may happen. In [5], the author refers that portfolio optimization as a management tool for electricity seller and buyers, it is also discussed how energy managers can allocate electricity among different negotiation opportunities (day-ahead markets, real time markets bilateral contracts, forward, etc.).

EM are usually composed by several different market types with different characteristics and time horizons. E.g. the dayahead spot market enables negotiating for the following day and bilateral contracts can be defined for a duration of years. This fact brings difficulties in the portfolio optimization, since the decisions for some trading can be less profitable in the future according to new information on prices. The consumers can take advantages when using a simulation with portfolio optimization, because there is a difference between signing a bilateral contract with a convention generation plant or signing 
it with a solar photovoltaic power plant, a wind power plant, or a combination of any these alternatives. E.g. consider a consumer that is able to set its own electricity contracts, and the consumption of this consumer has great electricity during the day, the solar photovoltaic power plant option is a good opportunity for setting a contract, because it has a great production during the day and when the production is low, the consumer can chose buy electricity on the spot market to supplement the contract previously established. The portfolio optimization is ideal tool for attempting to solve these types of problems [5].

This work proposes a methodology to enhance decision support of players' actions in EM, by identifying the most adequate actions that should be taken regarding EM participation, in order to maximize players' profits from negotiations, while minimizing the EM participation risk. The document is divided into five sections. Firstly, an introduction is made to the current status of power and energy systems, followed by the second section where a survey on the current state of the art of portfolio optimization in EM is presented. In the third section the general objective function, profit and risk function, as well as the considerations and constraints applied to the problem are presented. In the fourth section, the case study is presented, including a characterization of the case and the achieved results. Finally, the fifth section the conclusions are presented.

\section{PORTFOLIO OPTIMIZATION IN EM}

The first appearance of the theory of portfolios, goes back to 1952, when Harry Markowitz published his work [6] that had initially been applied in the area of economics and finance. From this appearance, more developments and applications occurred in other areas such as the EM.

The publication [5] titled, "Portfolio applications in electricity markets review: Private investor and manager perspective trends" presents a review on the application of Portfolios in the electric energy markets, the author presents a clear division between the application of portfolios to the private investors perspective and the perspective of manager trends.

The work presented in [7] performs a study about optimally allocation of energy production by generation company, among different markets, including spot, local and bilateral contract markets. In this study, the author was considered two different methods, one applying the Mean Variance Criterion and the other one the Conditional Value at Risk. In case study were used real data from a real PJM electricity market.

In [8] "Analytic Methods for Energy Diversity \& Security", the Mean Variance Portfolio Optimization is used to identify the optimal base load generation portfolios for large electricity generators in liberalized electricity markets. In this case the portfolio application arises for the need to support private investors in order to follow a two-step simulation approach to assess the impact of input (fuel) and production (electricity and $\mathrm{CO} 2$ ) risks on the return of different base load generation technologies.

According to [9] the risk management is an important and essential part in the generations companies' decision making.
In this case is formulated a general portfolio optimization problem for energy allocation problem between spot market and bilateral contracts, also [7] PJM electricity market prices are used. The author refers that have two ways to control the risk, one is through risk financing by using heeding to offset losses that can occur and the other is through risk reduction using diversification to reduce exposure to risk. Following the theory of Portfolio Selection present in [6], the greater the diversification of the asset portfolio, the less risk will be, going against the second form of risk control presented by the author.

In [10], the author applies the portfolio theory where it considers the existence of several markets with different characteristics, in this work the risk is not taken into account and only the profit of a determining player in the market is maximized. it is also considered that players can sell and buy electricity, as long as market rules allow it. The resolution of the optimization problem is performed by a random search method, where the performance of the method is also compared when it is imposed a valid initial solution or starting its search with a random solution.

In the literature, there are many works related to the application of portfolio optimization in the electric sector. The first application of portfolio theory in the electric sector was to find out the ideal investment (type of technology, location, installed power, etc.), as in the case of [11], [12], which referred to private investments in the electric energy sector.

\section{PROPOSED METHODOLOGY}

In 1950s Harry Markowitz developed the theory of Portfolio Selection, according to this theory, the investor should consider the trade-off between risk and return with risk being measured through the variance of asset returns. With this model is possible to construct an efficient frontier describing the optimal return for each possible of risk. This problem is known in economics and finance as the portfolio optimization problem [6]. In the proposed model, this concept is extended to incorporate the EM prices variability (and consequent associated forecasting error as the main component for risk definition).

\section{A. Objective function}

The presented methodology is characterized as a multiobjective problem where the two objectives are to maximize the profit and minimize the risk. The simplified problem formulation is presented in (1).

$$
\begin{gathered}
\operatorname{Max}\left[\lambda \times\left(f 1\left(\text { Spow }_{M \ldots N u m s}, \text { Bpow }_{M \ldots N u m M}\right)\right)-(1-\lambda)\right. \\
\left.\times\left(f 2\left(\text { Risk }_{d, p}\right)\right)\right]
\end{gathered}
$$

where $f 1$ represents the return and $f 2$ the risk; $\lambda$ is the tradeoff between profit and risk; $S p o w_{M}$ the volume to sell in market $M ;$ Bpow $_{M}$ volume to buy in session $S ; N u m M$ represents the number of considered markets; Risk $k_{d, p}$ represents the value of participation risk in $p$ period and $d$ day.

\section{B. Profit function}

Equation (2) represent the profit function, how can observe the first part represent the sales in different markets, the second part is the purchase in different markets, and the third the electricity production costs. 


$$
\begin{aligned}
& f 1\left(\text { Spow }_{\text {M...NumM }}, \text { Bpow }_{\text {M...NumM }}\right) \\
& =\left[\begin{array}{c}
\sum_{M=M 1}^{N u m M}\left(\text { Spow }_{d, p, M} \times p S_{M, d, p} \times \text { Asell }_{M}\right)- \\
\sum_{M=M 1}^{N u m M}\left(\text { Bpow }_{d, p, M} \times p B_{M, d, p} \times \text { Abuy }_{M}\right)- \\
\text { Cost }_{d, p}^{T E P}
\end{array}\right]
\end{aligned}
$$

where, Asell $_{M}$ and $A b u y_{M}$ represent the indication if this player can enter in negotiation in market $M$, and are boolean variables, Cost represents the function of production costs, $T E P$ represents the total electricity produced, $S p o w_{d, p, M}$ represents the amount of electricity to sell in market $M$, $B p o w_{d, p, M}$ represents the amount of electricity to buy in market Mand NumM represents the number of markets.

\section{Risk formulation}

Equation (3) represents the risk formulation, which is calculated based on the price forecasting error in each market, at each time. The training forecast error is used in risk formulation because it gives the indication of price instability in that market. As can be observed, in both cases the risk is considered, both in the purchase as in the sale. The error values depending on the market where the trading is performed will have different levels of risk, the error is different for each market and for each period.

$$
\begin{aligned}
& f 2\left(\text { Risk }_{d, p}\right) \\
& =\left[\begin{array}{c}
\sum_{M=M 1}^{N u m M}\left(\operatorname{Spow}_{M, d, p} \times p S_{M, d, p} \times \operatorname{error}_{M, d, p}\right)+ \\
\sum_{M=M 1}^{N u m M}\left(\operatorname{Bpow}_{M} \times p B_{M, d, p} \times \operatorname{error}_{M, d, p}\right)
\end{array}\right]
\end{aligned}
$$

where, $\operatorname{error}_{M, d, p}$ represent the error for market $M$, day $d$ and period $p$.

\section{Considerations and constrainsts}

$$
\begin{aligned}
& \forall d \in N \text { day, } \forall p \in N \text { per }, \text { Asell }_{M} \in\{0,1\}, \text { Abuy } \in\{0,1\}, \lambda \\
& \in\{0,1\} \\
& p S_{M, d, p} \\
& =\left\{\begin{array}{c}
\text { Forecast }_{M, d, p}^{A N N} \quad \text { if } M \notin \text { bilateral contracts } \\
\text { Value }\left(\operatorname{Spow}_{d, p, M}\right) \quad \text { if } M \in \text { bilateral contracts }
\end{array}\right. \\
& p B_{M, d, p} \\
& =\left\{\begin{array}{c}
\text { Forecast }_{M, d, p}^{A N N} \quad \text { if } M \notin \text { bilateral contacts } \\
\text { Value }\left(\text { Bpow }_{d, p, M}\right) \quad \text { if } M \in \text { bilateral contacts }
\end{array}\right. \\
& T E P=\sum E_{\text {Energy }} \text { prod } \\
& \text { Energy }_{\text {prod }} \in\left\{\text { Renew }_{\text {prod }}, \text { Therm }_{\text {prod }}\right\} \\
& \operatorname{Cost}_{d, p}^{T E P}=a \times \text { Therm }_{\text {prod }}{ }^{2}+b \times \text { Therm }_{\text {prod }}+c
\end{aligned}
$$

where Forecast ${ }_{M, d, p}^{A N N}$ represents the price forecasting value of $A N N$ for market $M$, day $d$, and period $p$, Value $\left(\operatorname{Spow}_{d, p, M}\right)$, $\operatorname{Value}\left(B p o w_{d, p, M}\right)$ represents the values of price for amount electricity in bilateral contracts, Energy $y_{\text {prod }}$ represents the electricity produced by the player, Renew $w_{\text {prod }}$ represents the renewable electricity produced, Therm prod $_{\text {represent the }}$ thermoelectric electricity produced and $a, b$ and $c$ represents the coefficients of marginal cost.

From equations (5) and (6) it can observed that two different types of prices are considered, the prices for bilateral contracts and prices from auction based markets. The origin of two different prices is caused by the characteristic of the markets, because in bilateral contract the price of electricity is highly variable depending on the amount of traded electricity, for estimation this values is used the clustering and fuzzy techniques, which can be seen in more detail in [13]. In other markets the electricity price is independent of the amount negotiated, this way an Artificial Neural Network is used [14]. The equation (7), (8) and (9) refers to the player production.

Equation (10) represents the main constrain of the problem, and represents the total electricity reserved to be sold in the set of all markets is never higher than the total expects production of the player, plus the bought electricity in all markets in the same period.

$$
\begin{gathered}
\sum_{M=M 1}^{N u m M} \text { Spow }_{M} \leq T E P+\sum_{M=M 1}^{N u m M} \text { Bpow }_{M} \\
0 \leq \text { Renew }_{\text {prod }} \leq \text { Max }_{\text {prod }} \\
\text { Min }_{\text {prod }} \leq \text { Therm }_{\text {prod }} \leq \text { Max }_{\text {prod }}, \text { if } \text { Therm }_{\text {prod }}>0 \\
0 \leq T E P \leq T E P_{\text {max }}
\end{gathered}
$$

Equations (11), (12) and (13) represent constrains more specific for the characteristics of each player.

\section{CASE STUDY}

This section is divided into 2 subsections, in A the case study is presented and in B the results are presented.

\section{A. Characterization}

The case study was created based on the actual functioning of EM, using the historical prices of the Iberian Electricity Market (MIBEL) [15]. The simulations performed correspond to 1 day and 24 periods, considering in total five markets namely: day-ahead spot market, bilateral contracts, a local market and two negotiation sessions of the balancing market. It is considered the possibility of buying and selling electricity in the same period, so that the scenario becomes more realistic specific rules have been created. Sales are carried out in all markets. In the case of purchases, the Spot market is excluded, the quantity of purchase in each market is limited to $10 \mathrm{MW}$, and own production (TEP) is also limited to $10 \mathrm{MW}$. These rules have been created to make the scenario as realistic as possible, and to try to demonstrate that the method is able to achieve results by complying with all constraints imposed.

All electricity produced is renewable thus not presenting costs in production. In balancing section, it is only possible to perform one of the actions, sell or buy electricity. In the markets for bilateral contracts and local market, it is possible to carry out both actions, and it is possible because the prices of electricity vary with the quantity negotiated, so it is possible to have different prices in the same market for the same period. 
This characteristic gives rise to the non-linearity of the problem. Since the solution of non-linear problems is difficult to be reached, i.e. usually requires a large computational time; a heuristic method has been chosen to solve the problem. The chosen heuristic was the Particle Swarm Optimization (PSO) [16], which is characterized by a random search defined by equations (14) and (15):

$$
\begin{gathered}
v_{i d}^{k+1}=w \cdot v_{i d}^{k}+c_{1} \cdot r_{1}^{k} \cdot\left(\text { Pbest }_{i d}^{k}-x_{i d}^{k}\right) \\
+c_{2} \cdot r_{2}^{k} \cdot\left(\text { Gbest }_{i d}^{k}-x_{i d}^{k}\right) \\
x_{i d}^{k+1}=x_{i d}^{k}+v_{i d}^{k+1}
\end{gathered}
$$

where, $v_{i d}^{k}$ is velocity of particle $\mathrm{i}$, parameter $\mathrm{d}$ and iteration $\mathrm{k}$, $x_{i d}^{k}$ is position of particle $\mathrm{i}$, parameter $\mathrm{d}$ and iteration $\mathrm{k}, k$ represent the current iteration, Pbest is personal best, Gbest is global best, $w$ is inertia term, $c_{1}$ is local attraction term, $c_{2}$ is global attraction term, $r_{1}, r_{2}$ are random numbers between $[0,1]$.

The PSO requires that each particle has an initial position (solution) to start the search process, hence, these are randomly generated. Departing from these positions, the particles start their search according to equations (14) and (15). The position resulting from each new iteration is compared with the previous one, and if it is better in terms of objective function this is saved. The inertia factor has an important role throughout the search process, so it may have influence on how the research expands in the space of research or contracting to refine a good solution, is defined by the equation (16), called Oscillating Inertia Weight [17].

$$
\begin{gathered}
w_{k}=\frac{w_{\min }+w_{\max }}{2}+\frac{w_{\max }-w_{\min }}{2} \cos \left(\frac{2 \pi k}{T_{k}}\right) \\
T_{k}=\frac{2 S_{1}}{3+2 k^{*}}
\end{gathered}
$$

The case study was tested on a computer compatible with 1 processor Intel ${ }^{\circledR}$ Xeon ${ }^{\circledR}$ W3 $35653.20 \mathrm{GHz}$, with 4 Cores, 8GB of RAM and the operating system Windows 10 64bits.

\section{B. Results}

The results presented in this section relate to the first period of negotiation, and since the PSO is a random method and does not guarantee optimal solution, 1000 instances were executed in each period.

Figure 1 presents the profit and risk associated to an experimental case study considering the application of the proposed portfolio optimization model for different markets.

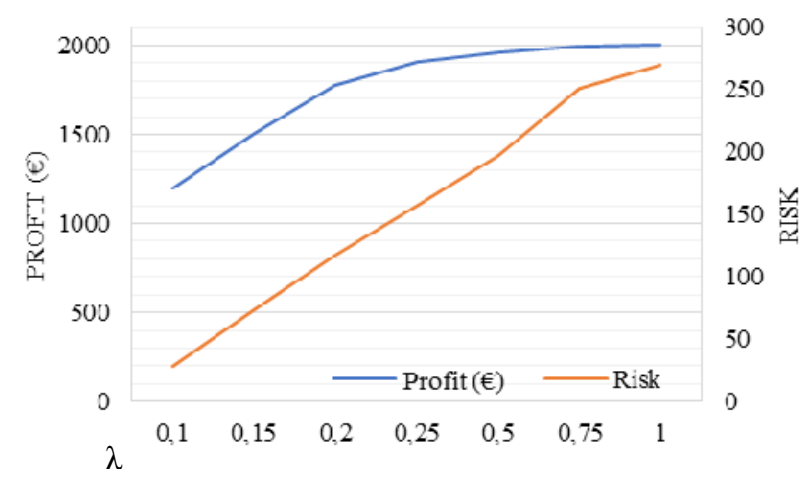

Figure 1. Profit and risk evaluation
Figure 1 represents the evolution of profit and risk values with increased exposure to risk $\lambda$. When the $\lambda=1$ represent the maximum exposure to the risk, and obtained the maximum value of profit, around $2000 €$.

In Figure 2, the Pareto frontier is presented for the results obtained, in the $y$ axis the profit value in $€$ is present, and in the $x$-axis, the value of the risk. As you can see, the higher the value of profit, the higher the risk. In the graph the points in green are the points corresponding to optimized $\lambda$ values, the line in blue may represent a continuous function if it is estimated.

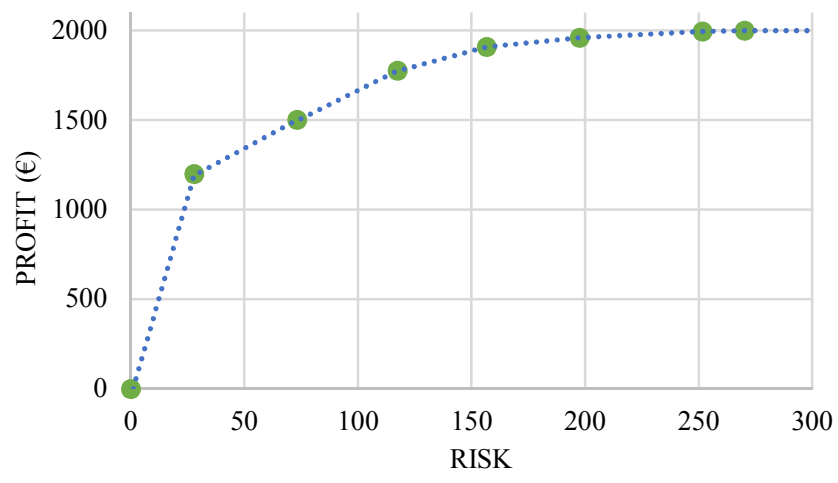

Figure 2. Pareto frontier

TABLE I presents the results of the objective function (Eq. (1)), profit function (Eq. (2)) and risk function (Eq. (3)).

TABLE I. OPTIIZATION RESULTS

\begin{tabular}{|c|c|c|c|}
\hline$\lambda$ & Eq. (1) & Eq. (2) & Eq. (3) \\
\hline 0,1 & 94,8 & 1200 & 28 \\
\hline 0,15 & 163,3760394 & 1503,813881 & 73,17181499 \\
\hline 0,2 & 261,6825225 & 1777,974476 & 117,3904658 \\
\hline 0,25 & 360,0775738 & 1910,617189 & 156,7689646 \\
\hline 0,5 & 881,3755462 & 1960,391441 & 197,6403489 \\
\hline 0,75 & 1435,232968 & 1997,525641 & 251,6450509 \\
\hline 1 & 2000,645575 & 2000,645575 & 270,2140623 \\
\hline
\end{tabular}

In TABLE I, the values of Eq. (2) and Eq. (3) represent the values of profit and risk respectively presented in Figure 1. All values in TABLE I for each risk level, are the maximum value found in the 1000 instances.

Figure 3 shows the values of risk for all markets, these values of risk are defined accordingly to the errors obtained by the EM forecasting and estimation methods. It is possible to observe that the balancing market - session 2 is the one where the error is greater, followed by the local SG market. The dayahead Spot market is the one that presents the smallest error.

By matching Figure 1, TABLE I. Oand Figure 3 it is possible to observe the relationship between the error value of the forecasting / estimation methods, profit and risk. In the TABLE I, as we can see the values of risk and profit are increasing with the value of $\lambda$, which corresponds to the expected because the higher the exposure to risk the more possibility there is to obtain higher profits. 


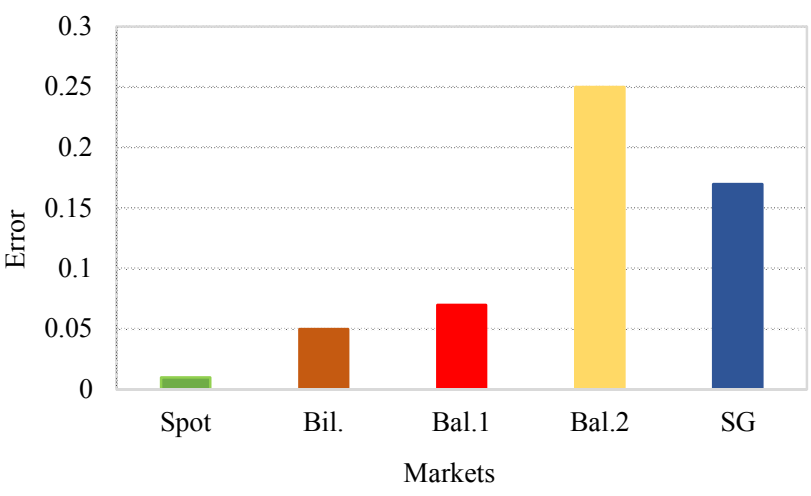

Figure 3. Risk values of all markets

Through TABLE II can be observed the allocation of sales in the different markets, for the different levels of exposure to risk.

TABLE II. TOTAL SALES IN THE MARKETS

\begin{tabular}{|c|c|c|c|c|c|}
\hline \multirow{2}{*}{$\lambda$} & \multicolumn{5}{|c|}{ Markets sales (MW) } \\
\cline { 2 - 6 } & Spot & Bil. & Bal. 1 & Bal. 2 & SG \\
\hline 0,1 & 20 & 0 & 0 & 0 & 0 \\
\hline 0,15 & 12,10 & 11,5 & 0 & 0 & 0 \\
\hline 0,2 & 33,87 & 0 & 0 & 0 & 0 \\
\hline 0,25 & 22,56 & 11,5 & 0 & 0 & 0 \\
\hline 0,5 & 20,18 & 11,50 & 0 & 0 & 2,79 \\
\hline 0,75 & 16,14 & 11,5 & 0 & 0 & 7,00 \\
\hline 1 & 14,64 & 11,5 & 0 & 0 & 8,58 \\
\hline
\end{tabular}

The allocation in all markets increases with the exposure to risk, i.e. if the risk exposure is greater, large amount of electricity are allocated to markets where the error is greater. Doing the analyses of local SG market, when the risk exposure is small $(\lambda=0.1)$, the methodology allocates the electricity sales to the markets in which the value of error is smaller. This is visible when the model allocates the electricity in Spot market because it is the market that has the smaller error. As can be seen, when the risk exposure increases, the model will allocate the electricity in markets in which the error value is bigger, as observed in TABLE II the case of Spot and SG markets, As it is possible to observe in Figure 3 the SG market has a greater error than the Spot, then the model as the risk exposure increases will allocate more electricity in the SG and remove it from the Spot, this happens because the profit of the market sale in SG is higher. As it is possible to verify in the balancing market sessions, there are no sales, because as it will be possible to observe in the TABLE III the model will buy electricity in these markets.

TABLE III presents the allocation of purchases in the all markets for all different levels at exposure of risk.

The exposure to the risk has similar influence on the purchases. The purchase in Bilateral contracts shown in TABLE III are increasing with the increase in risk exposure $\lambda$, which makes sense, because the greater the risk exposure, more electricity must be purchased. As the total electricity can be purchased in each market is $10 \mathrm{MW}$, and as can be seen from the TABLE III, in none of the markets this value exceeds the limit. In the case of balancing market sessions, when the exposure to risk is maximum, the model will buy the maximum amount in both markets, but as can be seen in balancing market session 2, the evolution differs from balancing 1 , which is influenced by the error value, since it presents a higher error value and thus the model only allocates the purchase on electricity when the risk exposure is higher. As can also be seen, in these two markets only the purchase is made, as this operation invalidates the sale of electricity.

TABLE III. TOTAL PURCHASES IN THE MARKETS

\begin{tabular}{|c|c|c|c|c|c|}
\hline \multirow{2}{*}{$\lambda$} & \multicolumn{5}{|c|}{ Markets buys (MW) } \\
\cline { 2 - 6 } & Spot & Bil. & Bal. 1 & Bal. 2 & SG \\
\hline 0,1 & 0 & 0 & 10 & 0 & 0 \\
\hline 0,15 & 0 & 3,60 & 10 & 0 & 0 \\
\hline 0,2 & 0 & 3,87 & 10 & 10 & 0 \\
\hline 0,25 & 0 & 4,06 & 10 & 10 & 0 \\
\hline 0,5 & 0 & 4,48 & 10 & 10 & 0 \\
\hline 0,75 & 0 & 4,64 & 10 & 10 & 0 \\
\hline 1 & 0 & 4,72 & 10 & 10 & 0 \\
\hline
\end{tabular}

TABLE IV. RESUltS OF PSO PERFORMANCE

\begin{tabular}{|c|c|c|c|c|c|c|}
\hline \multirow{2}{*}{$\lambda$} & \multicolumn{2}{|c|}{ Iterations } & \multicolumn{2}{c|}{$\begin{array}{c}\text { Time } \\
\text { (seconds) }\end{array}$} & \multicolumn{2}{c|}{$\begin{array}{c}\text { Objective } \\
\text { function }\end{array}$} \\
\cline { 2 - 7 } & Mean & Std & Mean & Std & Mean & Std \\
\hline 0,1 & 161,0 & 112,2 & 62,4 & 64,0 & 50,7 & 10,0 \\
\hline 0,15 & 223,5 & 76,1 & 90,0 & 65,1 & 135,8 & 6,9 \\
\hline 0,2 & 234,1 & 82,5 & 91,6 & 65,3 & 232,9 & 11,6 \\
\hline 0,25 & 252,1 & 81,7 & 117,9 & 90,9 & 333,3 & 18,1 \\
\hline 0,5 & 321,8 & 68,2 & 153,6 & 107,1 & 865,3 & 33,5 \\
\hline 0,75 & 332,2 & 59,4 & 189,0 & 135,0 & 1419,9 & 40,4 \\
\hline 1 & 331,7 & 60,6 & 177,4 & 124,0 & 1978,5 & 50,3 \\
\hline
\end{tabular}

TABLE IV shows the PSO performance results, these results were obtained in 1000 executions. In TABLE IV, the STD represents the standard deviation of the 1000 results. As it can be observed, the values of both parameters increase with the level of exposure to the risk. In TABLE IV, the values of Objective function were obtained with application of equation (1), and the maximum values for this equation are present in TABLE I.

\section{CONCLUSION}

The model proposed in this paper optimizes players' EM participation with a portfolio optimization. This model takes into account the maximization of the profit and minimization of the negotiating risk. From the presented results, it is possible to verify the relationship between the error of the forecasting / estimation of the price of electricity and the profit of the distribution of electricity in the different markets. The presented model proved to be efficient as it respected the restrictions 
imposed on it, as it is the case of the purchase in the Spot market to be impossible, and the case of the balancing market where it is only possible to execute an action. Comparing the presented methodology with the ones in the literature, where for the calculation of the risk historical values are used. In this case it is different because it is considered the error that the future value of electricity price may contain.

The PSO also proves to be efficient in solving the problem, since it presents credible results and with acceptable execution times, since this type of problems execution time is a critical factor. This resolution hence has advantages against an exact resolution where the execution time is much larger.

As future work, the integration of more types of markets with new features is proposed. It is also an objective to be able to apply technical constraints, and also apply a multiobjective resolution method [18] that allows solving the problem without resorting or weighting factor $(\lambda)$ between the two functions (equation (2) and equation (3)).

\section{REFERENCES}

[1] H. Lund, Renewable Energy Systems, Renewable Energy Systems A Smart Energy Systems Approach to the Choice and Modeling of 100\% Renewable Solutions, 2nd Editio. 2014.

[2] European Commission, "Regulation No 443/2009 of the European Parliament and of the Council of 23 April 2009," Brussels, Belgium, 2009

[3] B. Singh, C. Pal, V. Mukherjee, P. Tiwari, and M. K. Yadav, "Distributed generation planning from power system performances viewpoints: A taxonomical survey," Renew. Sustain. Energy Rev., vol. 75, pp. 1472-1492, Aug. 2015.

[4] I. Praça, C. Ramos, Z. Vale, and M. Cordeiro, "MASCEM: a multiagent system that simulates competitive electricity markets," IEEE Intelligent Systems, vol. 18, no. 6. pp. 54-60, 2003.

[5] R. Pérez Odeh, D. Watts, and M. Negrete-Pincetic, "Portfolio applications in electricity markets review: Private investor and manager perspective trends," Renew. Sustain. Energy Rev., vol. 81, pp. 192-204, Jan. 2018.

[6] H. Markowitz, "Portfolio Selection," J. Finance, vol. 7, no. 1, p. 77, Mar. 1952.

[7] R. C. Garcia, V. González, J. Contreras, and J. E. S. C. Custodio, "Applying modern portfolio theory for a dynamic energy portfolio allocation in electricity markets," Electr. Power Syst. Res., vol. 150, pp. 11-23, Sep. 2017.

[8] F. A. Roques, D. M. Newbery, and W. J. Nuttall, "Portfolio Optimization and Utilities' Investments in Liberalized Power Markets," in Analytical Methods for Energy Diversity \& Security, Elsevier, 2008, pp. 219-246.

[9] M. Liu and F. F. Wu, "Portfolio optimization in electricity markets," Electr. Power Syst. Res., vol. 77, no. 8, pp. 1000-1009, 2007.

[10] R. Faia, T. Pinto, Z. Vale, and J. . Corchado, "An Ad-Hoc initial solution heuristic for metaheuristic optimization of energy market participation portfolios," Energies, vol. 10, no. 7, 2017.

[11] B. Krey and P. Zweifel, "Efficient Electricity Portfolios for Switzerland and the United States," Zurich, 2006.

[12] S. Awerbuch, "Building Capacity for Portfolio-Based Energy Planning in Developing Countries: Shifting the grounds for debate," Renew. Energy Energy Effic. Partnersh., 2004.

[13] R. Faia, T. Pinto, and Z. Vale, "Dynamic Fuzzy Clustering Method for Decision Support in Electricity Markets Negotiation," ADCAIJ Adv. Distrib. Comput. Artif. Intell. J., vol. 5, no. 1, p. 23, Jul. 2016.

[14] T. Pinto, T. M. Sousa, and Z. Vale, "Dynamic artificial neural network for electricity market prices forecast," Intelligent Engineering Systems (INES), 2012 IEEE 16th International Conference on. pp. 311-316, 2012.

[15] MIBEL, "Mercado Iberico de Eletrecidade," 27-Feb-2007. [Online]. Available: http://www.mibel.com/index.php?lang=pt. [Accessed:
27-Feb-2017].

[16] J. Kennedy and R. Eberhart, "Particle swarm optimization," Neural Networks, 1995. Proceedings., IEEE Int. Conf., vol. 4, pp. 1942 1948 vol.4, 1995.

[17] K. Kentzoglanakis and M. Poole, "Particle Swarm Optimization with an Oscillating Inertia Weight," in Proceedings of the 11th Annual Conference on Genetic and Evolutionary Computation, 2009, pp. 1749-1750.

[18] W. Deng, H. Zhao, X. Yang, J. Xiong, M. Sun, and B. Li, "Study on an improved adaptive PSO algorithm for solving multi-objective gate assignment," Appl. Soft Comput., vol. 59, no. Supplement C, pp. 288-302, 2017. 